\title{
An Atypical Presentation of IVC Thrombosis
}

\author{
Samantha Gelman*, Andrew Benin, Gregory Shimizu, Scott Kubomoto and Rajesh Gulati \\ RCH Community Hospital, USA
}

*Corresponding author: Samantha Gelman, RCH Community Hospital, USA

\begin{tabular}{lll}
\hline ARTICLE INFO & & ABSTRACT \\
\cline { 1 - 1 } Received: & & Citation: Samantha Gelman, Andrew Benin, Gregory Shimizu, Scott Kubomoto, Rajesh \\
Published: 13,2020 & & Gulati. An Atypical Presentation of IVC Thrombosis. Biomed J Sci \& Tech Res 25(5)-2020. \\
& BJSTR. MS.ID.004268.
\end{tabular}

Abbreviations: IVC: Inferior Vena Cava; DVT: Deep Vein Thrombosis; PTS: Post-

Thrombotic Syndrome

\section{Opinion}

Inferior vena cava (IVC) thrombosis is commonly caused by either a congenital anomaly or an IVC filter that was not previously removed. Other causes include inherited thrombophilia or acquired. It is found in $2.6 \%$ - $4 \%$ of patients with lower extremity deep vein thrombosis (DVT). The mortality rate of IVC thrombosis is twice as high as that of DVT. Morbidities include post-thrombotic syndrome (PTS), disabling venous claudication, pulmonary embolism, and venous ulceration. In one study the rate of recurrent DVT in iliocaval thrombosis was $73 \%$ in those with untreated residual outflow stenosis versus $13 \%$ in those who had stenting of residual stenosis. Here we present an atypical case of IVC thrombosis in a young male without any inherited or acquired risk factors.

\section{Case Description}

A 28-year-old male with no past medical history presented with persistent abdominal pain for two weeks. The pain had been gradually worsening with radiation to the back with associated symptoms of heaviness in bilateral lower extremities without any calf or leg tenderness. CT imaging demonstrated IVC thrombosis with extension into femoral and renal veins with retroperitoneal inflammation. On admission, the patient was found to have an elevated PTT 102.2, PT 16.8, fibrinogen of 885, D-dimer 1492 , and a normocytic anemia. He was started on a heparin drip. Echocardiogram showed normal left ventricular function with an ejection fraction of $55-60 \%$. The patient underwent ultrasound guided venogram which demonstrated a thrombus extending from the left common iliac vein into the inferior vena cava. Reconstitution of the IVC was not seen and catheter directed thrombolysis was performed. Patient then had a percutaneous mechanical thrombectomy of the left common iliac vein and IVC followed by placement of a new thrombolysis catheter. He subsequently underwent balloon angioplasty of the IVC and left common iliac vein with success at opening peri-aortic venous collaterals draining the left common iliac vein.

\section{Discussion}

The hypercoagulable work up for this patient was negative for Factor V Leiden, APCR, JAK 2 mutation, Protein C \& S \& AT-III deficiency, Prothrombin Gene, SPEP, UPEP, and homocysteine. Patient was found to have a positive anti-cardiolipin antibody, however, was lost to follow up. The most likely etiology of his thrombotic event is anatomical secondary to ileocaval thrombosis. Patient was to be on indefinite anti-coagulation (Apixaban) despite this being his known first thrombotic event. This case presentation is unusual as it shows evidence of a young adult presenting with IVC thrombosis without any predisposing factors. Most anatomical anomalies that are associated with this condition are involved in one of three categories infrarenal (i.e.: duplicate IVC), renal (accessory left renal vein) and suprarenal (congenital caval stenosis or atresia). It is important to include this diagnosis in your differential even in younger age groups as it is associated with significant morbidity and mortality. 


\section{ISSN: 2574-1241}

DOI: 10.26717/BJSTR.2020.25.004268

Samantha Gelman. Biomed J Sci \& Tech Res

(C) This work is licensed under Creative

Submission Link: https://biomedres.us/submit-manuscript.php

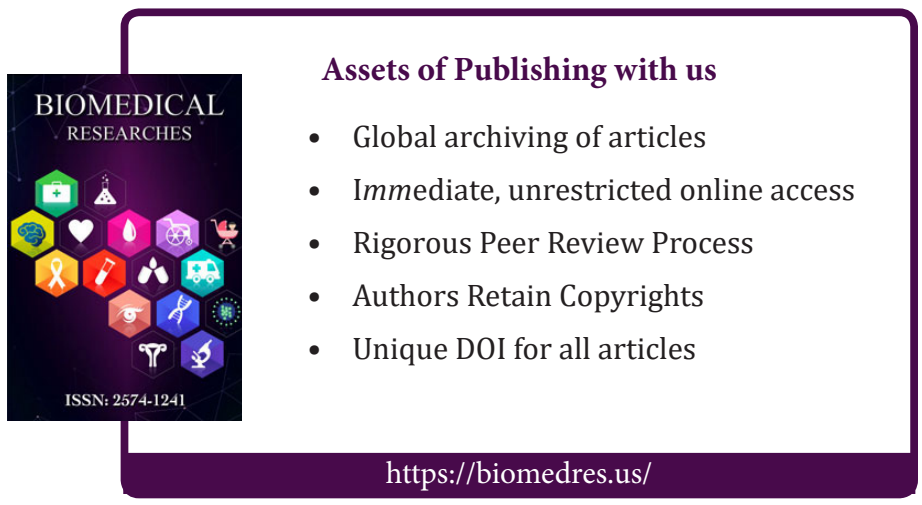

